\title{
Improving Remote Sensing-based Estimation of Mangrove Forest Gross Primary Production by Quantifying Environmental Stressors: Sea Surface Temperature, Salinity, and Photosynthetic Active Radiation
}

Yuhan Zheng ( $\nabla$ yuhan@g.ecc.u-tokyo.ac.jp )

University of Tokyo

Wataru Takeuchi

University of Tokyo

\section{Research Article}

Keywords: Mangrove forest, ecosystems, gross primary production, environmental stressors, sea surface temperature, salinity, photosynthetic active radiation

Posted Date: August 24th, 2021

DOI: https://doi.org/10.21203/rs.3.rs-817946/v1

License: (1) This work is licensed under a Creative Commons Attribution 4.0 International License.

Read Full License 
1 Improving remote sensing-based estimation of mangrove forest gross

2 primary production by quantifying environmental stressors: sea

3 surface temperature, salinity, and photosynthetic active radiation

4 Yuhan Zheng* and Wataru Takeuchi

5 Institute of Industrial Science, the University of Tokyo, Tokyo, 1538505, Japan

6 *yuhan@g.ecc.u-tokyo.ac.jp

7

8 ABSTRACT

9 Mangrove ecosystems play an important role in global carbon budget, however, the quantitative relationships between environmental drivers and productivity in these forests remain poorly understood. This study presented a remote sensing (RS)-based productivity model to estimate the light use efficiency (LUE) and gross primary production (GPP) of mangrove forests in China. Firstly, LUE model considered the effects of tidal inundation and therefore involved sea surface temperature (SST) and salinity as environmental scalars. Secondly, the downscaling effect of photosynthetic active radiation (PAR) on the mangrove LUE was quantified according to different PAR values. Thirdly, the maximum LUE varied with temperature and was therefore determined based on the response of daytime net ecosystem exchange and PAR at different temperatures. Lastly, GPP was estimated by combining the LUE model with the fraction of absorbed photosynthetically active radiation from Sentinel-2 images. The results showed that the LUE model developed for mangrove forests has higher overall accuracy $\left(\mathrm{RMSE}=0.0051, \mathrm{R}^{2}=0.64\right)$ than the terrestrial model $\left(\mathrm{RMSE}=0.0220, \mathrm{R}^{2}=0.24\right)$. The main environmental stressor for the photosynthesis of mangrove forests in China was PAR. The estimated GPP was, in general, in agreement with the in-situ measurement from the two carbon flux towers. Compared to the MODIS GPP product, the derived GPP had higher accuracy, with RMSE improving from 39.09 to $19.05 \mathrm{~g} \mathrm{C} / \mathrm{m}^{2} / 8$ days in 2012, and from 33.76 to $19.51 \mathrm{~g} \mathrm{C} / \mathrm{m}^{2} / 8$ days in 2015 . The spatiotemporal distributions of the mangrove GPP revealed that GPP was most strongly controlled by environmental conditions, especially temperature and PAR, as well as the distribution of mangroves. These results demonstrate the potential of the RS-based productivity model for scaling up GPP in mangrove forests, a key to explore the carbon cycle of mangrove ecosystems at national and global scales.

\section{Introduction}

Mangrove forest is one of the most carbon-rich ecosystems whose carbon sequestration is considerably 
understand the carbon cycle in mangrove ecosystems. Carbon flux data measured with eddy covariance (EC) techniques provide invaluable information on ecosystem productivities and can be used to establish productivity models ${ }^{2}$. However, these models were limited to a 0.1 to $2 \mathrm{~km}$ spatial footprint around the towers, and therefore, applying them at other sites remains challenging due to the variation of GPP across species, structural features, and latitudinal locations.

Remote sensing (RS) provides the opportunity to characterize the ecosystem structures and environmental conditions and therefore, estimate the productivity of the ecosystems ${ }^{3}$. The light use efficiency (LUE) model was widely adopted to estimate GPP ${ }^{4,5}$. Currently, GPP models for terrestrial forest are applicable on a global scale (e.g., C-fix, MOD17, and GLO-PEM) ${ }^{6-9}$, however, production models have not been evaluated and employed in mangrove forests in a large scale, mainly due to the lack of understanding of carbon exchange in mangrove forests and measurements from flux tower.

Compared to terrestrial ecosystems, mangrove ecosystems are periodically inundated by the tides which contribute to the waterlogged and high salinity soil environment. Although mangroves have developed special structures or tissues to adapt to such demanding surroundings such as the aerial root, thick canopy, and salt-tolerance tissues, the environmental stresses remain critical to mangrove productivity. In addition to being affected by air temperature ( $\left.\mathrm{T}_{\text {air }}\right)$ and vapor pressure deficit (VPD) as terrestrial forests ${ }^{10,11}$, mangrove forests are also influenced by the sea surface temperature (SST), salinity, and photosynthetic active radiation (PAR). Firstly, SST affects the roots and aboveground metabolism of mangroves ${ }^{12}$. The high SST would increase the respiration rate. To minimize the water loss and energy consumption, the stomatal conductance within the mangrove would be reduced, which could lower the mangrove light saturation point (LSP) and constrain the photosynthesis. Secondly, the salinity of surface water and porewater represents a significant control on the mangrove LUE which is strongly related to the sea surface salinity, rainfall, and river discharge ${ }^{13,14}$. The high salinity leads to the negative osmotic pressure in the environment of roots which limits the water supply, and therefore inhibits the photosynthesis net photosynthetic rate ${ }^{15,16}$. Thirdly, the relatively low LSP makes the mangrove easy to reach light-saturated status ${ }^{17}$. Hence, the high PAR condition would bring excess light absorption and heat to the canopy that reduces the LUE of the canopy. These typical environmental stressors are not well understood and quantified. Studies have typically focused on the seasonal dynamics and interannual variation of carbon fluxes through modeling GPP ${ }^{17-20}$ or tidal effects on $\mathrm{CO}_{2}$ exchange based on in-situ measurements ${ }^{21-24}$. Barr, et al. ${ }^{13}$ provided a satellite-driven model for estimating $\mathrm{CO}_{2}$ uptake in mangroves in the Florida Everglades, USA. For the first time, the effect of salinity on the mangrove LUE was investigated. Lele, et al. ${ }^{25}$ proposed a vegetation photosynthesis model which can be well applied to relatively small-scale mangrove forest by incorporating in-situ LUE and high-resolution environmental scalars.

Currently, there are no RS-based productivity products for mangrove forests globally. Therefore, scaling up carbon fluxes from flux tower to national and global scales considering the coastal 
environment is of great importance and challenge. Modeling the GPP of mangrove forests provides the first step in using RS to discover the role of mangrove ecosystems in global carbon budgets.

Therefore, the objectives of this study are 1) to improve the LUE model for mangroves considering environmental stresses in coastal zone (SST, salinity, and PAR), 2) to estimate the GPP of mangroves in the whole coastal zone of China combining flux tower-based measurements and RS, 3) to map the spatiotemporal distributions of mangrove productivity and analyze the possible affecting factors.

\section{Results}

Effects of environmental stressors on mangrove LUE.

$\boldsymbol{L} \boldsymbol{U} \boldsymbol{E}_{\boldsymbol{m a x}}$ : The $\mathrm{GPP}_{\max }$ and $\mathrm{R}_{\mathrm{e}}$ for two mangrove forests are summarized in Table 1 based on the flux tower data. The NEE-PAR fitted curves are displayed in Figure 1. The initial slope of each rectangular hyperbola was calculated as the $\mathrm{LUE}_{\max }$ and listed in Table 1 . When the $\mathrm{T}_{\text {air }}$ was the most suitable for mangroves growth $\left(21-25^{\circ} \mathrm{C}\right)$, the $\mathrm{LUE}_{\max }$ has the highest value (0.057); when the $\mathrm{T}_{\text {air }}$ was high ( $>$ $25^{\circ} \mathrm{C}$ ), the $\mathrm{LUE}_{\max }$ was the lowest. We adopted the $\mathrm{LUE}_{\max }$ for mangroves within the optimum $\mathrm{T}_{\text {air }}$.

Table 1 Parameters of three nonlinear hyperbolic models.

\begin{tabular}{llllll}
\hline & $\mathbf{T}_{\text {air }}$ & GPPmax & $\mathbf{R}_{\mathbf{e}}$ & LUEmax & $\mathbf{R}^{2}$ \\
& $\left({ }^{\circ} \mathrm{C}\right)$ & $\left(\mu \mathrm{mol} / \mathrm{m}^{2} / \mathrm{s}\right)$ & $\left(\mu \mathrm{mol} / \mathrm{m}^{2} / \mathrm{s}\right)$ & $(\mathrm{mol} \mathrm{C/mol} \mathrm{PPFD})$ & \\
\hline (a) & $>=25$ & 27.13 & -3.76 & 0.047 & 0.39 \\
(b) & $21-25$ & 26.12 & -3.22 & 0.057 & 0.55 \\
(c) & $<=21$ & 25.45 & -2.26 & 0.055 & 0.70 \\
\hline
\end{tabular}



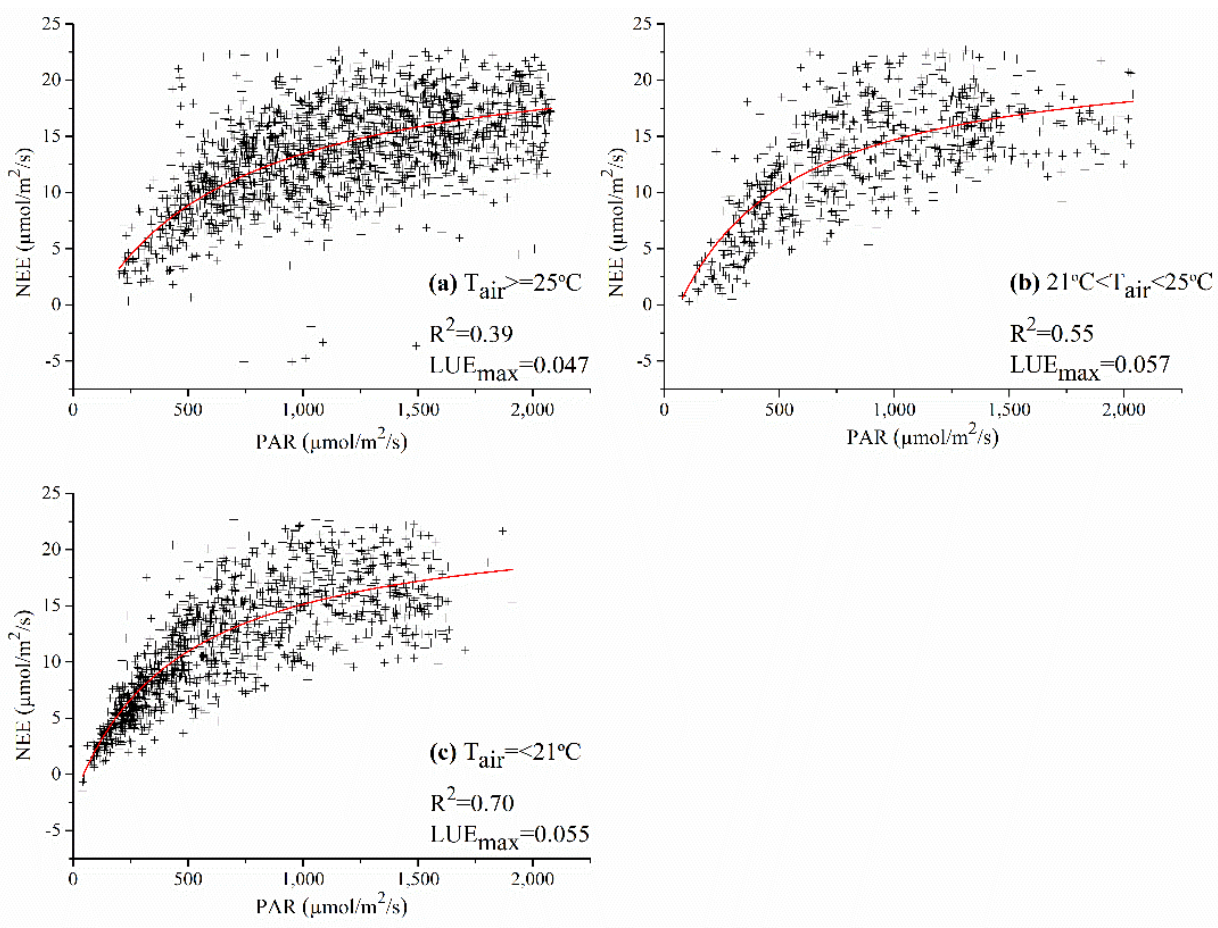

Figure 1. The responses of NEE to PAR at: (a) $\mathrm{T}_{\text {air }}>=25^{\circ} \mathrm{C}$, (b) $21{ }^{\circ} \mathrm{C}<\mathrm{T}_{\text {air }}<25^{\circ} \mathrm{C}$, and (c) $\mathrm{T}_{\text {air }}<=$ $21{ }^{\circ} \mathrm{C}$.

$\boldsymbol{T}_{\text {air scalar }}$ and $\boldsymbol{S S \boldsymbol { S }} \boldsymbol{T}_{\text {scalar }}$ : The diurnal relationships between GPP and $\mathrm{T}_{\text {air }}$ were similar among four seasons, which were displayed in Fig. S1. The GPP typically increased with the increasing $\mathrm{T}_{\text {air }}$ and attained its maximum at noon. The highest GPP occurred when the $\mathrm{T}_{\text {air }}$ was around $25-30{ }^{\circ} \mathrm{C}$. The empirical values of $T_{\min }, T_{\max }, T_{\text {opt }}$ from previous studies were summarized in Table $\mathrm{S} 1$. In general, mangroves cannot adequately develop when the mean $\mathrm{T}_{\text {air }}$ is below $10^{\circ} \mathrm{C}$, which corresponds with the SST around $12{ }^{\circ} \mathrm{C}$ during the coldest time of the year. While mangroves are intolerant to freezing temperatures below $0^{\circ} \mathrm{C}$ for both $\mathrm{T}_{\text {air }}$ and SST ${ }^{16}$. Photosynthetic activities of most mangroves are strongly restricted when the $\mathrm{T}_{\text {air }}$ exceeds $35^{\circ} \mathrm{C}^{26}$ and SST is over $32^{\circ} \mathrm{C}$. The optimal $\mathrm{T}_{\text {air }}$ is remarkably similar to the previous estimate of about $25^{\circ} \mathrm{C}$. Based on the literature review and in-situ data analysis, we ultimately adopted $10{ }^{\circ} \mathrm{C}, 28{ }^{\circ} \mathrm{C}$ and $35{ }^{\circ} \mathrm{C}$ for $\mathrm{T}_{\text {air min }}, \mathrm{T}_{\text {air opt, }}$ and $\mathrm{T}_{\text {air max }}$ and $12{ }^{\circ} \mathrm{C}, 24{ }^{\circ} \mathrm{C}$, and $32{ }^{\circ} \mathrm{C}$ for $\mathrm{SST}_{\min }, \mathrm{SST}_{\mathrm{opt}}$, and $\mathrm{SST}_{\max }$, respectively. $\boldsymbol{V P D}_{\text {scalar }}$ : Table S2 lists the VPD values in global mangrove forests from previous studies. $\mathrm{VPD}_{\max }$ in mangrove forests ranged from 1.15 to $4.5 \mathrm{kPa}$, and $\mathrm{VPD}_{\min }$ was around $0.09-1.18 \mathrm{kPa}$. Most mangroves grew properly at VPD values of between 0.44 and $1.37 \mathrm{kPa}^{11,27,28}$, so finally, we adopted the VPD values of $0.6 \mathrm{kPa}$ and $4 \mathrm{kPa}$ as $\mathrm{VPD}_{\min }$ and $\mathrm{VPD}_{\text {max }}$ to parameterize the $\mathrm{VPD}_{\text {scalar }}$ for mangrove ecosystems.

Salinity $_{\text {scalar: }}$ Fig. S2 compared the RS-based salinity with in-situ salinity and daily rainfall. From this figure, we can clearly see that RS-based salinity differed significantly from the measured salinity. Barr, et al. ${ }^{29}$ ) found that the surface water salinities above $28 \mathrm{ppt}$ result in reduced NEE and LUE of 
mangroves. As the surface water salinity is usually lower than the sea water salinity due to the rainfall and river discharge, we assumed that surface water salinity is lower than $28 \mathrm{ppt}$ if the RS-based sea water salinity is below $28 \mathrm{ppt}$. Therefore, a constraint was finally added to the calculation of $\mathrm{Sal}_{\text {scalar, }}$ which is equal to 1 when the salinity is below $28 \mathrm{ppt}$.

$\boldsymbol{P A R}_{\text {scalar: }}$ LUE declined with the increasing PAR as shown in Figure 2. However, the decreasing rates changed with the increase of PAR. When PAR values were less than $1 \mathrm{mmol} / \mathrm{m}^{2} / \mathrm{s}$, the decreasing rate was high. While when PAR exceeds $1 \mathrm{mmol} / \mathrm{m}^{2} / \mathrm{s}$, the decreasing rate became lower. Therefore, we set the threshold of PAR to get the decreasing rate of $\mathrm{PAR}_{\text {scalar }}$. The $\mathrm{m}_{\mathrm{par}}$ for PAR $<=1 \mathrm{mmol} / \mathrm{m}^{2} / \mathrm{s}$ and PAR $>1 \mathrm{mmol} / \mathrm{m}^{2} / \mathrm{s}$ were $0.5171 \mathrm{mmol} / \mathrm{PAR}$ and $0.3080 \mathrm{mmol} / \mathrm{PAR}$.
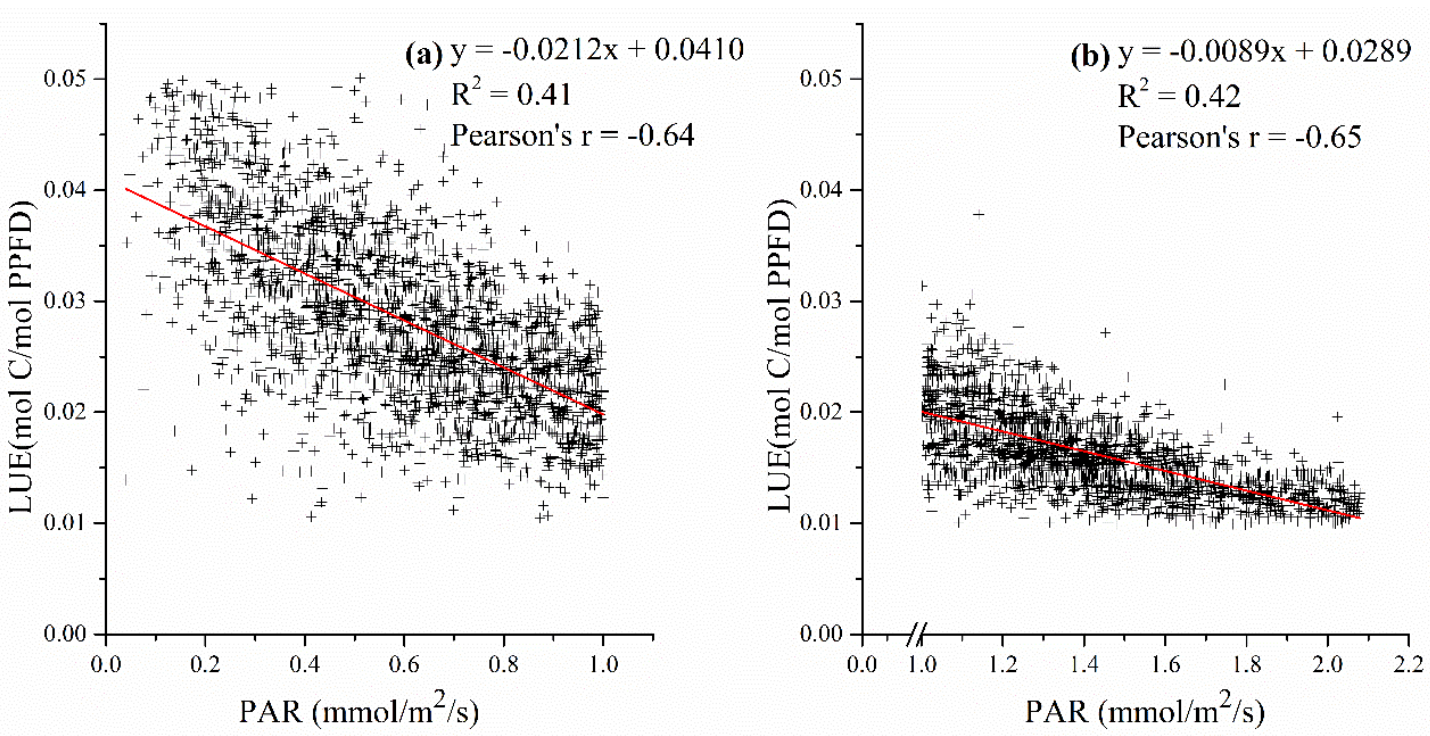

Figure 2. The response of LUE to PAR: (a) $\mathrm{PAR}=<1 \mathrm{mmol} / \mathrm{m}^{2} / \mathrm{s}$ and (b) $\mathrm{PAR}>1 \mathrm{mmol} / \mathrm{m}^{2} / \mathrm{s}$.

\section{LUE validation.}

Figure 3 shows the validation results of the terrestrial LUE model and mangrove LUE model considering coastal environments, with hourly data (Figure 3a-b) and daily data (Figure 3c-d). LUE estimated by the mangrove model had higher accuracies with lower RMSE. LUE estimated with hourly meteorological data exhibited similar results and accuracies with the ones using daily scale data.

Fig. S3 assessed the performance of each newly introduced variable on estimating LUE. Results showed that the LUE estimated with $\mathrm{SST}_{\text {scalar }}$ and $\mathrm{Sal}_{\text {scalar }}$ maintained lower accuracies with RMSE $=0.0185-0.0203, \mathrm{R}^{2}=0.2264-0.2332$, and Pearson's $r=0.48-0.49$. However, $\mathrm{PAR}_{\text {scalar }}$ performed well in estimating LUE and exhibited a high consistency with the measured LUE (RMSE $=0.0048$, $\mathrm{R}^{2}=0.7147$, and Pearson's $\mathrm{r}=0.85$ ). 

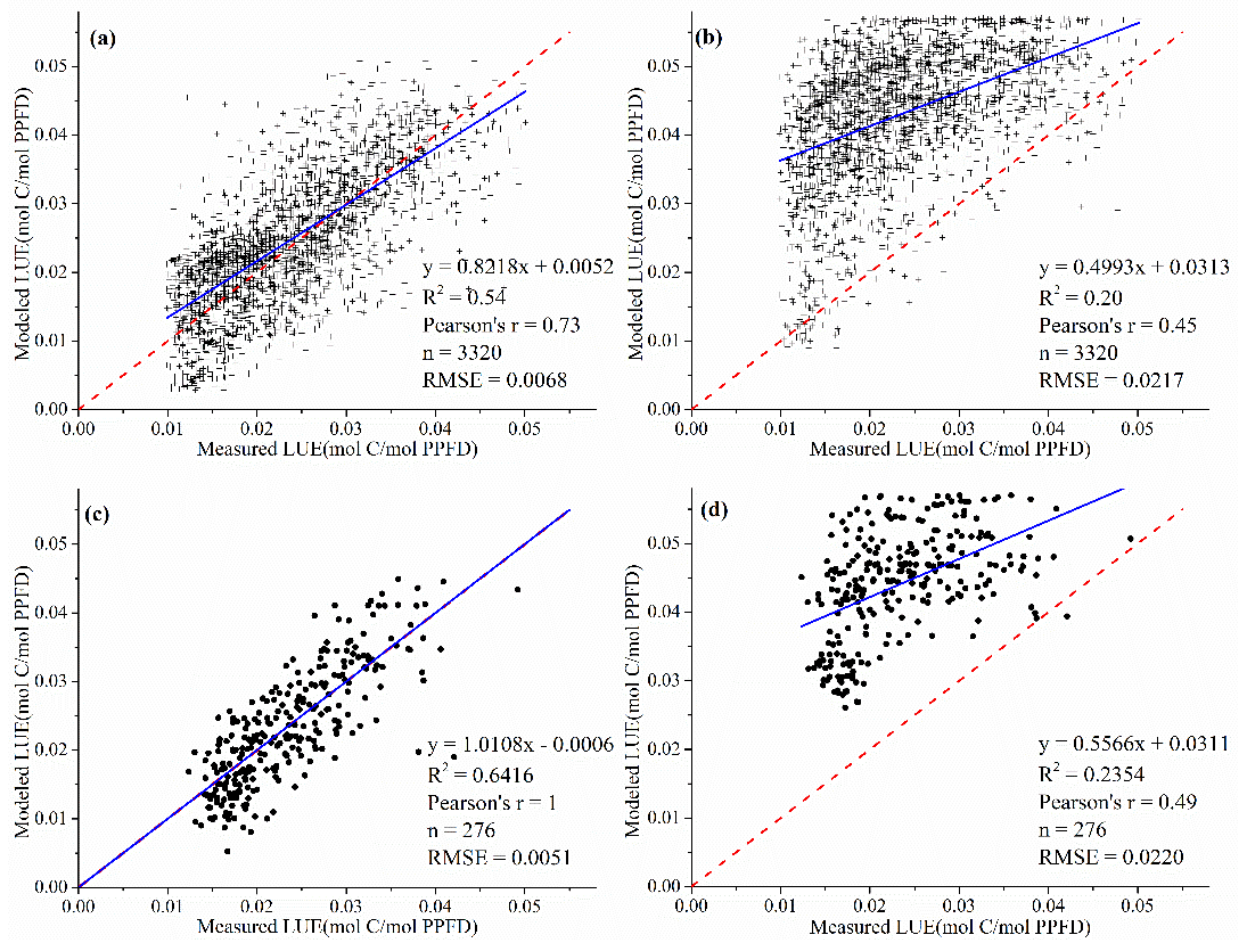

Figure 3. Validation of LUE estimated from terrestrial (b\&d) and mangrove model (a\&c) with daily(c\&d) and hourly-scale (a\&b) data.

\section{GPP validation.}

134 The validation results for the GPP model are shown in Figure 4. The results reveal that the GPP has relatively high accuracies with Pearson's $r$ around 0.5 and RMSE less than $7 \mu \mathrm{mol} / \mathrm{m}^{2} / \mathrm{s}$. The GPP estimated was generally lower than the measured value. Figure 5 compares the time-series GPP results from MODIS, flux tower measurements, and model estimations. GPP estimated from our model had similar trends with the measured values, while MODIS GPP products have larger fluctuance. Modeled GPP had higher accuracies compared with MODIS GPP products which improved the RMSE from 39.09 to $19.05 \mathrm{~g} \mathrm{C} / \mathrm{m}^{2} / 8$ days in 2012 and from 33.76 to $19.51 \mathrm{~g} \mathrm{C} / \mathrm{m}^{2} / 8$ days in 2015 .
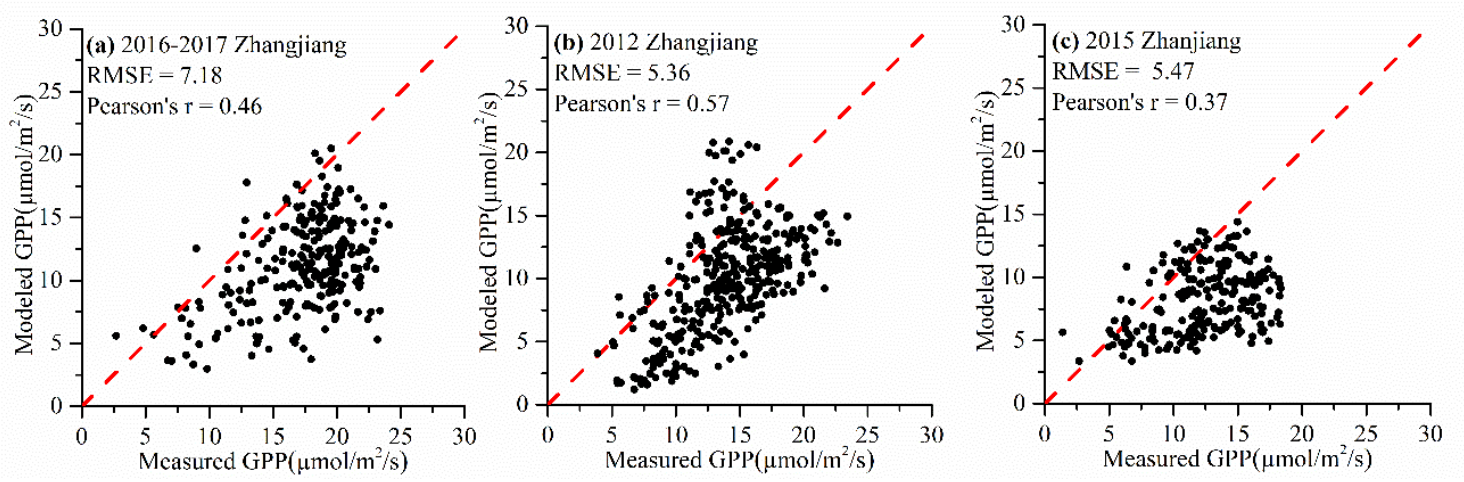

Figure 4. Validation of modeled GPP with flux-tower data from (a) Zhangjiang (2016-2017), (b) 

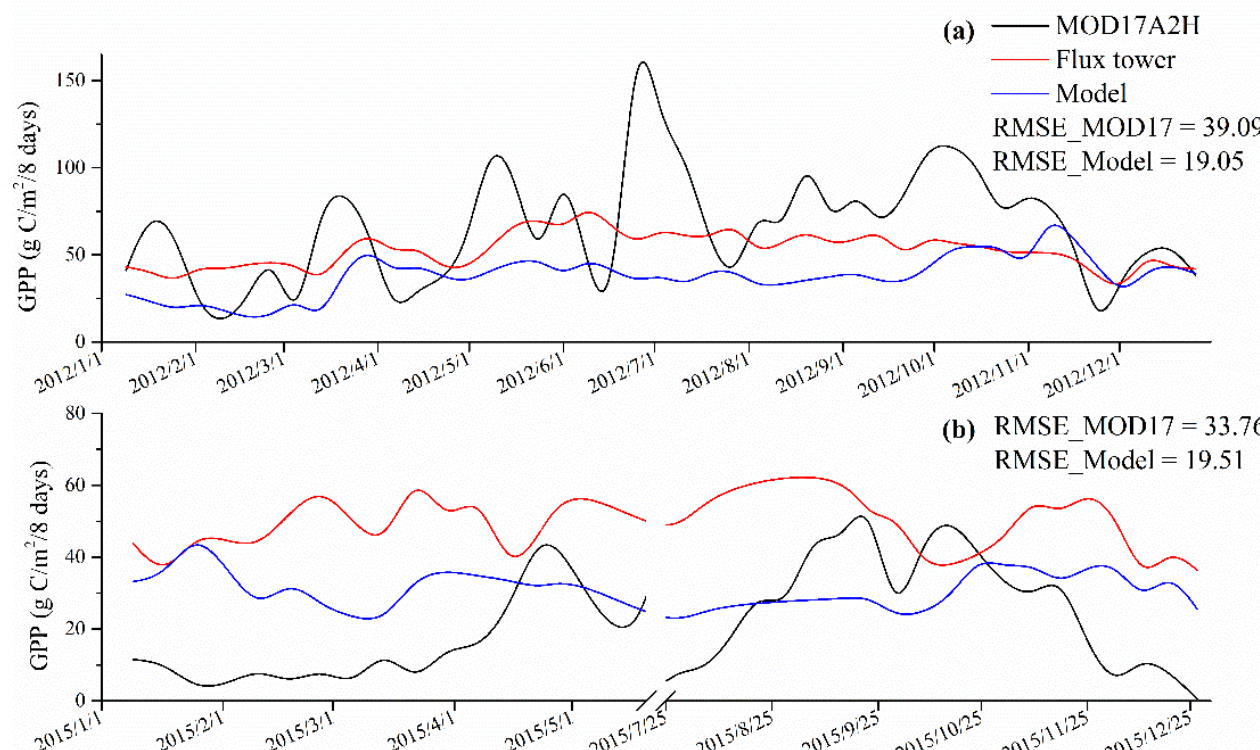

(b) RMSE_MOD17 $=33.76$ RMSE_Model $=19.51$

Figure 5. Time-series GPP comparisons among MODIS products, in-situ measurements and mangrove GPP model generated in this study: (a) Zhangjiang (2012) and (b) Zhanjiang (2015).

\section{Spatiotemporal distributions of GPP.}

The seasonal and spatial distributions of GPP along the coastline are illustrated in Figure 6 . The overall

GPP values were similar in all four seasons, fluctuating between 0.1 and $0.2 \mathrm{~mol} / \mathrm{m}^{2} /$ day, with slightly

lower values in summer, mostly below $0.1 \mathrm{~mol} / \mathrm{m}^{2} /$ day, and higher values in spring and autumn, with average values around $0.2 \mathrm{~mol} / \mathrm{m}^{2} /$ day. In winter, GPP values were significantly lower in the high latitude zone, mostly below $0.1 \mathrm{~mol} / \mathrm{m}^{2} /$ day. At low latitudes, GPP increased with the decreasing latitude, especially below $20^{\circ} \mathrm{N}$, up to $0.25 \mathrm{~mol} / \mathrm{m}^{2} /$ day.
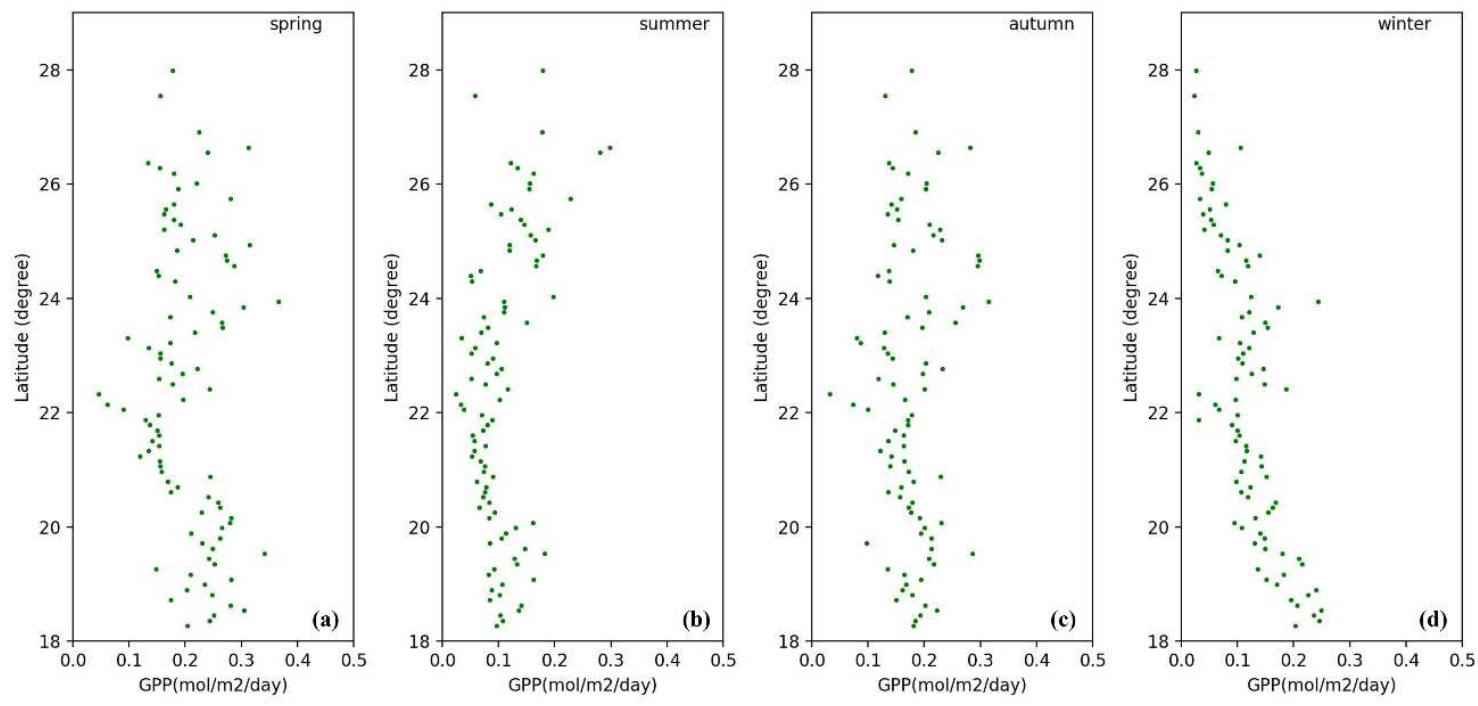

Figure 6. Seasonal and spatial variations of GPP in the whole mangrove forests in 2018: (a) spring,

(b) summer, (c) autumn, and (d) winter. 

increased from 2007 to 2018 , with average values of $0.13 \mathrm{~mol} / \mathrm{m}^{2} /$ day, $0.14 \mathrm{~mol} / \mathrm{m}^{2} /$ day, and 0.15 $\mathrm{mol} / \mathrm{m}^{2} /$ day for 2007,2010 , and 2018, respectively. Along the coastline, the spatial variations of GPP were similar. GPP tended to increase with the latitude below $22^{\circ} \mathrm{N}$, reaching a maximum GPP of about $0.2 \mathrm{~mol} / \mathrm{m}^{2} /$ day at $18^{\circ} \mathrm{N}$.

162

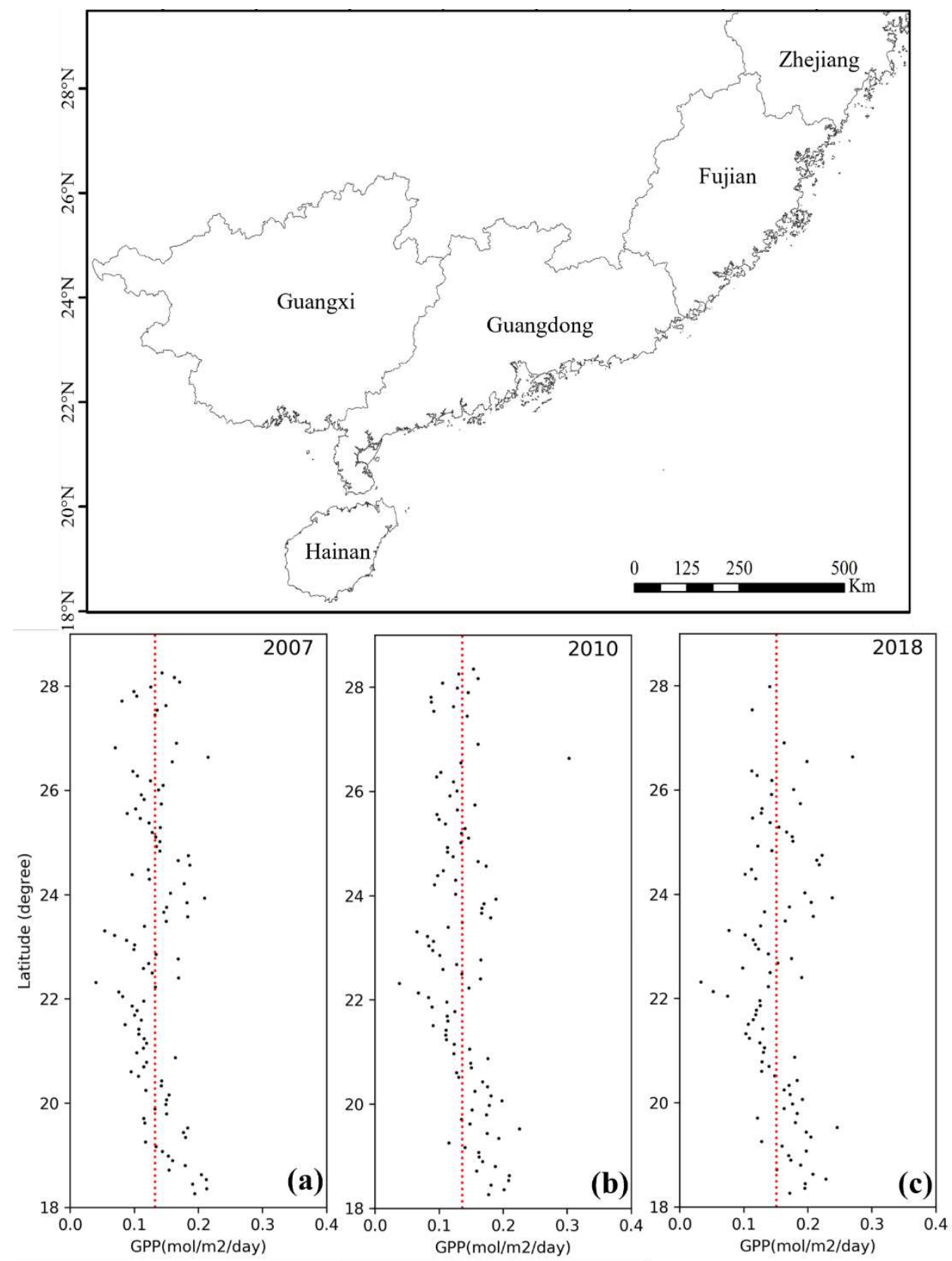

Figure 7. Spatiotemporal distributions of GPP in mangrove forests over China: (a) 2007, (b) 2010, and (c) 2018.

\section{Discussion}


The improved performance of the mangrove LUE model considering coastal environments in this study was mainly attributed to the determination of environmental scalars. Parameters determining environmental stressors (e.g., $T_{\text {opt }}, T_{\min }, T_{\max }, V P D_{\min }$, and $V P D_{\max }$ ) were set based on the general characteristics of mangroves worldwide. It may not be as accurate for the mangroves in our study sites, but it generally reflects the response of mangroves to environmental changes and is applicable to other study sites. Despite the specific characteristics of each mangrove ecosystem at different sites being preferred, however, this study first offers the possibility to estimate mangrove productivity at a larger scale to track GPP, thus emphasizing the role of mangrove ecosystems nationally or worldwide.

The validation results showed that the LUE values of the mangrove model agreed well with those estimated by EC method (Figure 3 ) and indicated improved performance (slope $=0.8218-1.0108$, intercept $=-0.0006-0.0052, \mathrm{R}^{2}=0.54-0.64, \mathrm{RMSE}=0.0051-0.0068$, Pearson's $\left.r=0.73-1\right)$, compared to the existing terrestrial LUE model (slope $=0.4993-0.5566$, intercept $=0.0311-0.0313, \mathrm{R}^{2}=0.24$ 0.45, RMSE $=0.0217-0.0220$, Pearson's $r=0.45-0.49$ ). Firstly, the RS-based LUE model for terrestrial forest ecosystems considers only the environmental stressors of $\mathrm{T}_{\text {air }}$ and VPD. The photosynthesis in mangrove forests is influenced by other unique environmental factors caused by tidal inundation. According to Fig. S3, PAR caused the most significant effect on LUE, which is consistent with previous studies ${ }^{13,29,30}$. The impact of SST has not been quantitatively assessed, however, SST is a global control that determines the upper limit of the latitudinal range of mangroves ${ }^{12,31}$. In our study, the effects of SST and salinity on the mangrove LUE were quantified and helped improve LUE modeling in mangrove ecosystems.

Secondly, LUE $E_{\max }$ was typically defined for different land covers, however, there were no specific values for mangrove forests. In this study, the LUE $E_{\max }$ of mangroves was first determined. It is worth noting that daytime NEE responses to PAR vary depending on the $\mathrm{T}_{\text {air }}{ }^{22,29,32}$ so that ${ }^{2} E_{\max }$ was determined separately at high, optimal, and low temperatures. The results showed that $L E_{\max }$ reached a maximum when $T_{\text {air }}$ was within the optimal range for mangroves, which represents the high productivity of mangrove ecosystems. Furthermore, the estimated LUE $\max _{\max }$ of mangrove forests $(0.057)$ was larger than most terrestrial forests ${ }^{33-35}$, which could contribute to the high production and carbon sequestration in mangrove forests.

Lastly, the relatively low stomatal conductance of mangroves leads to low LSP compared with terrestrial forests, which could result in the high-irradiance stress for photosynthesis ${ }^{36,37}$. Mangrove LSP ranges from about 0.2 to $1.2 \mathrm{mmol} / \mathrm{m}^{2} / \mathrm{s}$, depending on the species and environments ${ }^{38-40}$. LUE was relatively low in April and May when seasonal PAR was high, as photosynthesis is more likely to reach saturation. Therefore, we assumed the LUE of mangroves decreased with increasing PAR. In addition, we found that the downscaling effect of PAR on LUE was not constant, but varied with increasing PAR. As follows, different PAR scalars were set for mangroves according to different PAR values. This is a critical first attempt at refining PAR $_{\text {scalar, }}$ which represents a significant departure from 
the assumption of a constant downscaling effect of PAR in RS-driven models ${ }^{13,41}$. The accuracy of the LUE model was improved by modifying the PAR $_{\text {scalar }}$ with different downscaling slopes, especially in periods of high PAR values.

Compared with the results obtained from flux-tower measurements, the modeled GPP was basically within the confidence interval of the measured results. The annual averages of GPP in Zhangjiang were $1,729 \mathrm{~g} \mathrm{C} / \mathrm{m}^{2} / \mathrm{yr}$ and 1,924 g C/m²/yr, in 2012 and 2016, and the annual mean value of GPP in Zhanjiang was $1,434 \mathrm{~g} \mathrm{C} / \mathrm{m}^{2} / \mathrm{yr}$ in 2015 . The previous study showed that the GPP in Zhangiiang ranged from 1,763 to $1,919 \mathrm{~g} \mathrm{C} / \mathrm{m}^{2} / \mathrm{yr}$ with a mean value of $1,871 \mathrm{~g} \mathrm{C} / \mathrm{m}^{2} / \mathrm{yr}^{30,42,43}$, which is in good agreement with the estimated values obtained in this study. Liu and Lai ${ }^{44}$ ) reported that the GPP of the Mai Po mangrove reserve was $2,827 \mathrm{~g} \mathrm{C} / \mathrm{m}^{2} / \mathrm{yr}$. Rodda, et al. ${ }^{19}$ ) found a GPP value of $1,271 \mathrm{~g} \mathrm{C} / \mathrm{m}^{2} / \mathrm{yr}$ for Sunderbans mangroves in India. Gnanamoorthy, et al. ${ }^{45}$ ) estimated a GPP of $2,305 \mathrm{~g} \mathrm{C} / \mathrm{m}^{2} / \mathrm{yr}$ for Pichavaram mangroves. Variations in these estimates across sites were possibly caused by different climate-hydrological conditions, mangrove species, and ages. Differences in the same location may be due to different time scales and different methods of data gap filling and flux partitioning.

In a similar way to the GPP model for terrestrial ecosystems ${ }^{46}$, the effect of the mangrove GPP model on the accuracy of GPP estimates can vary considerably under different environmental conditions. However, in comparison with the accuracy of models built for other vegetation types, the GPP model in this study performed substantially in two sites with RMSE of $2.54-3.41 \mathrm{~g} \mathrm{C} / \mathrm{m}^{2} /$ day. Wang, et al. ${ }^{47}$ ) adopted different models to estimate GPP for global vegetation and validation results showed the RMSE ranged from 1.79 to $2.33 \mathrm{~g} \mathrm{C} / \mathrm{m}^{2} /$ day. Xiao, et al. ${ }^{48}$ ) demonstrated that the deviation between observed and predicted GPP was about $35-282 \mathrm{~g} \mathrm{C} / \mathrm{m}^{2}$ in an evergreen needleleaf forest. Also, the absolute GPP errors were $7.94-20.92 \%$ and $9.97-13.70 \%$ for maize cropland and degraded grassland ${ }^{34}$. Despite the discrepancy, our results were generally consistent with previous studies and were verified by field observations to be more similar to mangrove productivity near the flux towers.

The MODIS GPP and EC-estimated GPP showed that the MODIS GPP had a large fluctuation and weakly reflects productivity, being overestimated in 2012 and underestimated in 2015. The response of mangrove productivity to $\mathrm{T}_{\text {air }}$ has not been well-calibrated in the MODIS GPP product, which may partly account for the poor correlation between the MODIS GPP and EC estimates. However, the GPP model generated in our study showed similar trends to the field measurements, capturing seasonal variations. Additionally, the increased difference in MODIS GPP versus EC estimates may be due to the structure of the MODIS, which assumes a linear increase of GPP with PAR. In our model, the response of GPP to PAR is suppressed, resulting in seasonal changes in GPP that better match the observations.

Most studies provide EC-based estimates of GPP that are measurements from a limited footprint. It is possible to extrapolate results across similar vegetation types and geographic settings, but not to 
areas of heterogeneous vegetation. The RS-based GPP model offers spatial-scale estimates that can be directly incorporated into ecosystem-type models. PAR, SST, and salinity are the key environmental parameters of this RS-based mangrove GPP model. SST and salinity data were derived from the satellite images, while PAR was generated from the reconstructed PAR data, given that is more accurate than the available RS data and available for historical years of data. However, there are already some RS-based PAR products from Hamawari-8, MERIS, and SeaWiFS, which provide an opportunity to obtain large-scale PAR data using RS in the future. In addition to this, GPP of two mangrove forests was assessed and validated with three-year measurements. Validation at different sites and years showed similar results, which indicated the model has similar performance across mangrove forests. Nonetheless, these estimates need to be corroborated with EC databases, which are relatively accurate and provide many additional variables that are currently beyond the scope of higher spatial-resolution RS estimates. The proposed GPP model considering coastal environments was well

The LUE model considering the effects of SST, salinity, and PAR performed well, however, the GPP estimated from the LUE, fAPAR, and PAR showed discrepancies and were generally lower than the measured values. Although the results are better than MODIS products, limitations exist still.

Firstly, the effects of salinity and SST on mangrove productivity were directly related to tide activities. The soil pore water and surface water salinity could affect the osmotic pressure of mangroves especially for the submerged parts which would control the stomatal conductance. In the same way, SST could roughly represent the temperature of mangrove root systems and soil sediments which has impacts on mangrove roots' respiration and transpiration. Therefore, the tide duration, tide height, and tide cycle would determine the effect of salinity and SST on the mangrove LUE and GPP. However, quantifying the influence from the tidal cycle remains a challenging task, which could influence the performance of salinity scalar $_{\text {and }} \mathrm{SST}_{\text {scalar }}$.

Secondly, mangroves of different species and ages exhibit diverse structural and physical conditions, resulting in different $L U E_{\max }$, and optimal growing conditions such as $\mathrm{T}_{\text {air opt }}$ and $\mathrm{VPD}_{\min }$. However, we have not specified the variables for different mangrove species and ages which could be improved in the future.

Thirdly, the relatively low spatial and temporal resolution of the environmental data from RS would influence the accuracy of the model. The datasets have a relatively coarse resolution (usually $500 \mathrm{~m}-1 \mathrm{~km}$ ) and are thereby less suitable for smaller nature reserves, especially in the narrow patches of mangrove areas that are rapidly being exploited in coastal China. Besides, VPD is on a monthly scale, which is less consistent with in-situ measurements. Porewater salinity is controlled by sea surface salinity, precipitation, and river discharge. However, currently, pore water salinity was expressed in terms of sea surface salinity, which may lead to an underestimation of Sal scalar. Finer resolution and meteorological data are highly needed to improve the model performance more 
significantly.

Lastly, the RS-derived fAPAR only considers the absorptions by living green vegetation elements, whereas the ground measured fAPAR refers to the contributions from all absorbing components ${ }^{49}$. The lower fAPAR-S2 values in mangrove forests may be due to the exposed-to-air root systems which absorb the radiation. Moreover, the spatial distribution of PAR was determined by CoKriging interpolation. The elevation was taken as the covariate to estimate spatial PAR. There are many other variables affecting the incoming PAR (e.g., slope and clearness) ${ }^{50}$. A more comprehensive set of variables needs to be included in the Co-kriging interpolation to improve the PAR estimation.

The spatial and seasonal variation of the mangrove GPP was related to environmental changes along the shoreline. The low summer GPP was explained by the lower fAPAR in summer compared with other seasons, which was principally due to the underestimation of fAPAR in summer.

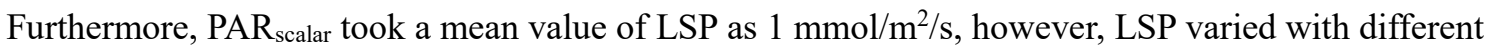
species and environmental conditions. In summer, mangroves are more likely to obtain light saturation,

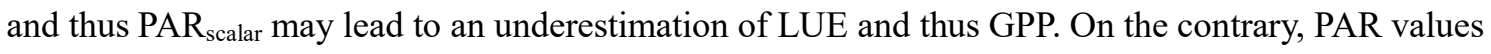
in winter were relatively low but increased slightly with decreasing latitude. Thus, the inhibitory effect of PAR on LUE was not significant, and GPP increased with decreasing latitude. Salinity and VPD were more stable across years and locations and had no noticeable effect on the mangrove LUE and GPP. The seasonal latitudinal patterns and effects on mangrove productivity were similar for $T_{\text {air }}$ and SST. $\mathrm{T}_{\text {air }}$ and SST were lower in winter, especially at high latitudes where mangroves were more sensitive to cold weather. Therefore, the GPP of mangroves at high latitudes in winter was the lowest throughout the year. However, hot weather in summer also limited the photosynthesis in mangroves, especially at low latitudes, where $\mathrm{T}_{\text {air }}$ and SST were higher. Nevertheless, there were some correlations among these environmental constants. For example, the $T_{\text {air }}$ affects the vapor pressure and SST. There was a positive correlation between PAR and $\mathrm{T}_{\text {air }}$. The multicollinearity among these variables and the various conditions of mangroves may affect the performance of the model and show variations along the coastline, which would be improved in future studies.

Additionally, the GPP of mangroves increased from 2007 to 2018, which was mainly due to the expansion of mangrove forests in the coastal areas. As mangroves grow, canopy size and tree density increase, which may lead to higher LUE and less underestimation of fAPAR, thus contributing to high productivity. However, Zhejiang province $\left(27^{\circ} 02^{\prime} \mathrm{N}-31^{\circ} 11^{\prime} \mathrm{N}\right)$ experienced extremely cold weather in January 2016 caused by the East Asia cold wave ${ }^{51,52}$, and large areas of mangrove forests died or became sick, leading to a decline in the mangrove GPP at high latitudes in 2018.

\section{Conclusion}

In conclusion, we presented a RS-based productivity model to estimate the GPP of mangrove forests in China. The model considered the environmental stressors induced by tidal inundation, therefore, involving SST, sea surface salinity, and PAR as environmental scalars to develop the LUE model. SST 
was first-ever included in the mangrove LUE model and parameterized by a similar model for $T_{\text {air. }}$ In addition, it was the first to indicate the downscaling effects of PAR on the mangrove LUE and determine the LUE $E_{\max }$ for mangroves under different temperatures. Consequently, the mangrove GPP was estimated based on the mangrove LUE model, fAPAR generated from Sentinel-2 images and reconstructed PAR from meteorological stations. The results revealed that PAR, $\mathrm{T}_{\text {air }}$, VPD, SST, and salinity are clearly drivers of diurnal and seasonal variations in the mangrove $\mathrm{LUE}$ and $\mathrm{CO}_{2}$ fluxes. Among them, PAR, SST, and salinity are unique to mangrove ecosystems. The LUE model developed for mangrove forests had higher overall accuracy $\left(\mathrm{RMSE}=0.0051, \mathrm{R}^{2}=0.64\right)$ than the previous LUE model for terrestrial forests $\left(\mathrm{RMSE}=0.0220, \mathrm{R}^{2}=0.24\right)$. GPP estimated in this study generally agreed with in-situ measurements from two carbon flux towers. Although there are still limitations, the modeled GPP maintained higher accuracies compared with MODIS GPP products. These results demonstrated the potential of RS-driven productivity models for the large-scale mangrove GPP estimation and provided fundamental data and scientific methodological support for future mangrove blue carbon potential assessment and restoration policy development.

\section{Materials and Methods}

\section{Study area.}

Two carbon flux towers have been established in Zhangjiang Estuary Mangrove National Nature Reserve $\left(117^{\circ} 24^{\prime} 53.02^{\prime \prime} \mathrm{E}, 23^{\circ} 55^{\prime} 26.63^{\prime \prime N}\right)$ in Fujian and Zhanjiang Mangrove National Nature Reserve $\left(110^{\circ} 09^{\prime} 44.67 " \mathrm{E}, 20^{\circ} 56^{\prime} 24.08^{\prime \prime} \mathrm{N}\right)$ in Guangdong (Fig. S4), China. The mangroves in Zhangjiang and Zhanjiang are mainly composed of Kandelia obovate and Sonneratia apetala. The forest structures and microclimate in these two sites were various and listed in Table S3. Site-specific data from carbon flux towers Half-hourly carbon fluxes between the canopy and atmosphere were obtained from flux towers and processed by the EC method. Meteorological and tidal information was measured with multiple instruments near the flux tower. All data were provided by the ChinaFlux network ( http://www.chinaflux.org ). Table S4 summarizes the data availability. More details of the EC system structure and data processing can be referred to in published papers ${ }^{17,30}$.

\section{Remote sensing data.}

339 Historical climate data were derived from different satellites or based on the reanalysis data. The 340 summary of the dataset can be found in Table 2. Climate data were obtained from the Google Earth 341 Engine platform. Sentinel-2 L1C images were adopted for computing the fraction of absorbed 342 photosynthetic active radiation (fAPAR). PAR was derived from the reconstructed PAR dataset ${ }^{53}$ 343 which was derived from the meteorological data, MODIS AOD data and NASA/GSFC O 3 data. Zheng and Takeuchi ${ }^{54}$ ) mapped the mangrove distributions in China for 2007, 2010, and 2018 which were used to determine the mangrove area. 
Table 2 Summary of the climatic data.

\begin{tabular}{cccc}
\hline & Dataset & Spatial resolution & Time resolution \\
\hline Tair & ERA5 reanalysis data & 0.25 degree & Daily \\
VPD & TerraClimate & 2.5 arc minutes & Monthly \\
SST & MODIS Aqua data & $500 \mathrm{~m}$ & Daily \\
Salinity & Hybrid Coordinate Ocean Modal (HYCOM) & 0.08 degree & Daily \\
PAR & Reconstructed PAR & point data & Daily \\
\hline
\end{tabular}

\section{Mangrove productivity estimation.}

Light use efficiency (LUE) modeling. LUE was estimated based on the vegetation type and environmental stress as the function of maximum LUE (LUE ${ }_{\max }$ ) and environmental scalars, which is shown in equation (1) ${ }^{41,55-57}$.

$$
\begin{gathered}
L U E=L U E_{\max } \times T_{\text {air scalar }} \\
\times V P D_{\text {scalar }}
\end{gathered}
$$

where $L U E_{\max }$ is the maximum LUE, $T_{\text {air scalar }}$ and $\mathrm{VPD}_{\text {scalar }}$ are the down-regulation scalars for the effects of $\mathrm{T}_{\text {air }}$ and water on LUE. However, the environmental factors affecting the mangrove photosynthetic metabolism have significant differences with terrestrial forests ${ }^{29,58,59}$. Although it is hard to isolate individual effects from these environmental factors without concurrent photochemical measurements, the diurnal and seasonal changing patterns revealed that the temperature ( $T_{\text {air }}$ and SST), PAR, VPD, and salinity represent the controlling factors of LUE variations on both diurnal and seasonal scales. Therefore, in this study, $\mathrm{T}_{\text {air }}, \mathrm{SST}$, PAR, VPD, and salinity were considered as the environmental stressors for the mangrove LUE and corresponding scalars were defined to establish the LUE model, which was proposed as:

$$
L U E=L U E_{\text {max }} \times T_{\text {air scalar }} \times V P D_{\text {scalar }} \times S S T_{\text {scalar }} \times \text { Salinity }_{\text {scalar }} \times P A R_{\text {scalar }}
$$
where $\mathrm{SST}_{\text {scalar, }}$ Salinityscalar, and $\mathrm{PAR}_{\text {scalar }}$ are the down-regulation scalars for the effects of SST, surface water salinity, and PAR on the mangrove LUE, respectively. The parameterizations of each environmental scalar are explained as follow:

$365 \boldsymbol{L} \boldsymbol{U E}_{\boldsymbol{m a x}}: \mathrm{LUE}_{\max }$ describes the maximum efficiency of vegetation for fixing solar energy and is 366 typically related to the chlorophyll content, leaf age, species, light intensity, and growth stages ${ }^{60}$. The 367 LUE $_{\max }$ of MODIS GPP/NPP Project were derived for 12 biomes including evergreen needleleaf forest, evergreen broadleaf forest, deciduous needleleaf forest, deciduous broadleaf forest, mixed forest, 
closed shrubland, open shrubland, woody savanna, savanna, grassland, and cropland ${ }^{35}$. However, no existing $L_{U E} E_{\max }$ is available for mangrove forest. We adopted the nonlinear hyperbolic model (Michaelis-Menten function) as equation (3) to simulate the relationship between net ecosystem exchange (NEE) and PAR which was widely used for terrestrial vegetations ${ }^{34,57,61}$.

$$
N E E=\frac{L U E_{\max } \times P A R \times G P P_{\max }}{L U E_{\max } \times P A R+G P P_{\max }}+R_{e}
$$

where GPP $\mathrm{max}_{\max }$ is the maximum GPP over a year, and $\mathrm{R}_{\mathrm{e}}$ is the ecosystem respiration at night. LUE $_{\max }$ was determined by fitting the light response curves (NEE versus PAR) with the daytime half-hourly NEE and PAR values from the growing seasons of mangroves (September to February in Zhangjiang). As the responses of NEE to PAR were related to $\mathrm{T}_{\text {air }}{ }^{29}, \mathrm{LUE}_{\max }$ may vary under different $\mathrm{T}_{\text {air. }}$ The optimal $\mathrm{T}_{\text {air }}$ for mangroves is $21-25^{\circ} \mathrm{C}$, so we set the $\mathrm{T}_{\text {air }}$ ranges as: $\mathrm{T}_{\text {air }}<=21^{\circ} \mathrm{C}, 21{ }^{\circ} \mathrm{C}<\mathrm{T}_{\text {air }}<25^{\circ} \mathrm{C}$, and $\mathrm{T}_{\text {air }}>=25^{\circ} \mathrm{C}$. LUE $\max$ was determined for each temperature range.

$\boldsymbol{T}_{\text {air scalar }}$ and $\boldsymbol{S S} \boldsymbol{T}_{\text {scalar }}$ : Mangrove photosynthesis is restricted to a certain optimum temperature range for $\mathrm{T}_{\text {air }}$ and SST. The low temperature may freeze the water-conducting xylem vessels of the mangrove, and the high temperature would reduce the stomatal conductance ${ }^{58}$. So, we assumed that the mangrove LUE increases with the increase of temperature, however, it will start to decrease after a certain value. Therefore, $\mathrm{T}_{\text {scalar }}$ was defined as equation (4) which was proposed by Raich, et al. ${ }^{62}$ ) for different vegetations.

$$
T_{\text {scalar }}=\frac{\left(T-T_{\min }\right)\left(T-T_{\max }\right)}{\left(T-T_{\min }\right)\left(T-T_{\max }\right)-\left(T-T_{\text {opt }}\right)^{2}}
$$

where $T_{\min }, T_{\max }$, and $T_{\text {opt }}$ are minimum, maximum, and optimal temperatures for the mangrove photosynthetic activities, respectively. If $\mathrm{T}_{\text {air }}$ is below $\mathrm{T}_{\text {min }}, \mathrm{T}_{\text {scalar }}$ is set to be zero. The daily mean temperature $\left(\mathrm{T}_{\text {mean }}\right)$ and daily maximum temperature $\left(\mathrm{T}_{\max }\right)$ were employed to calculate the daytime $\mathrm{T}_{\text {air }}$ following equation (5) ${ }^{63}$.

$$
T_{\text {air }}=\frac{\left(T_{\text {mean }}+T_{\text {max }}\right)}{2}
$$

Although $\mathrm{T}_{\text {scalar }}$ was originally developed for the terrestrial forest, Barr, et al. ${ }^{13}$ ) quantified it in the mangrove LUE model. In this study, we adopted the empirical values to estimate the $T_{\max }, T_{\min }$, and $\mathrm{T}_{\mathrm{opt}}$ and then validated them with the GPP- $\mathrm{T}_{\text {air }}$ relationship based on the in-situ measurements. The photosynthetic responses of mangrove to SST are similar to $\mathrm{T}_{\text {air }}$, so we assume it follows the same function but unique characteristics $\left(\mathrm{SST}_{\max }, \mathrm{SST}_{\min }\right.$, and $\mathrm{SST}_{\mathrm{opt}}$ ). Therefore, the $\mathrm{T}_{\text {scalar }}$ for $\mathrm{SST}$ $\left(\mathrm{SST}_{\text {scalar }}\right)$ was derived in the same way as $\mathrm{T}_{\text {air scalar. }}$

$\boldsymbol{V P D}_{\text {scalar }}$ VPD $\mathrm{V}_{\text {scalar }}$ is saturated at both maximum and minimum VPD and can be calculated by equation (6) ${ }^{35}$.

$$
V P D_{\text {scalar }}=\frac{V P D_{\max }-V P D}{V P D_{\max }-V P D_{\min }}
$$

where $\mathrm{VPD}_{\max }$ and $\mathrm{VPD}_{\text {min }}$ are the maximum and minimum daytime VPD. If VPD is less than $\mathrm{VPD}_{\min }$, 
$\mathrm{VPD}_{\text {scalar }}$ is set to be 1 . If VPD is larger than $\mathrm{VPD}_{\max }, \mathrm{VPD}_{\text {scalar }}$ will be set as 0 . We determined $\mathrm{VPD}_{\text {min }}$ and $\mathrm{VPD}_{\max }$ by summarizing from previous studies and verified with in-situ data.

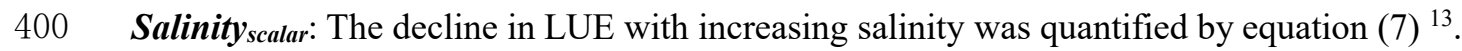

$$
\text { Sal }_{\text {scalar }}=1-\text { Salinity } \times m_{\text {sal }}
$$

where $\mathrm{m}_{\text {sal }}$ represents the decreasing rate of $\mathrm{Sal}_{\text {scalar }}$ in response to the increasing salinity. The $\mathrm{m}_{\text {sal }}$ was estimated at $0.0047 \pm 0.0022^{13}$. Consequently, we employed $\mathrm{m}_{\text {sal }}$ as 0.0047 to determine the salinity scalar for mangrove ecosystems.

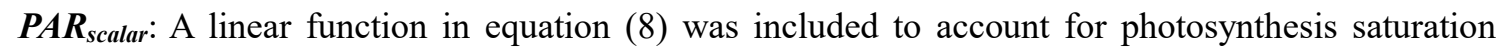
manifested as declining LUE with increasing PAR.

$$
P A R_{\text {scalar }}=1-P A R \times m_{\text {par }}
$$

where $m_{\text {par }}$ represents the decreasing rate of PAR ${ }_{\text {scalar }}$ to the increasing PAR. The $m_{\text {par }}$ was determined by the response of LUE to increasing PAR.

Gross primary production (GPP) modeling. GPP was calculated as equation (9) ${ }^{4,64}$ and the overall flowchart can be summarized as Figure 8:

$$
G P P=P A R \times f A P A R \times L U E
$$

Firstly, the LUE of mangroves in these two mangrove reserves was calculated based on the LUE model proposed in section 2.4.1. Resampling of RS data was carried out to keep the spatial resolution at 500 $\mathrm{m}$ and the temporal resolution at daily. Since SST and salinity were derived from the sea surface, the nearest sea surface pixel to the mangrove was adopted to represent the effects of SST and salinity on mangrove LUE.

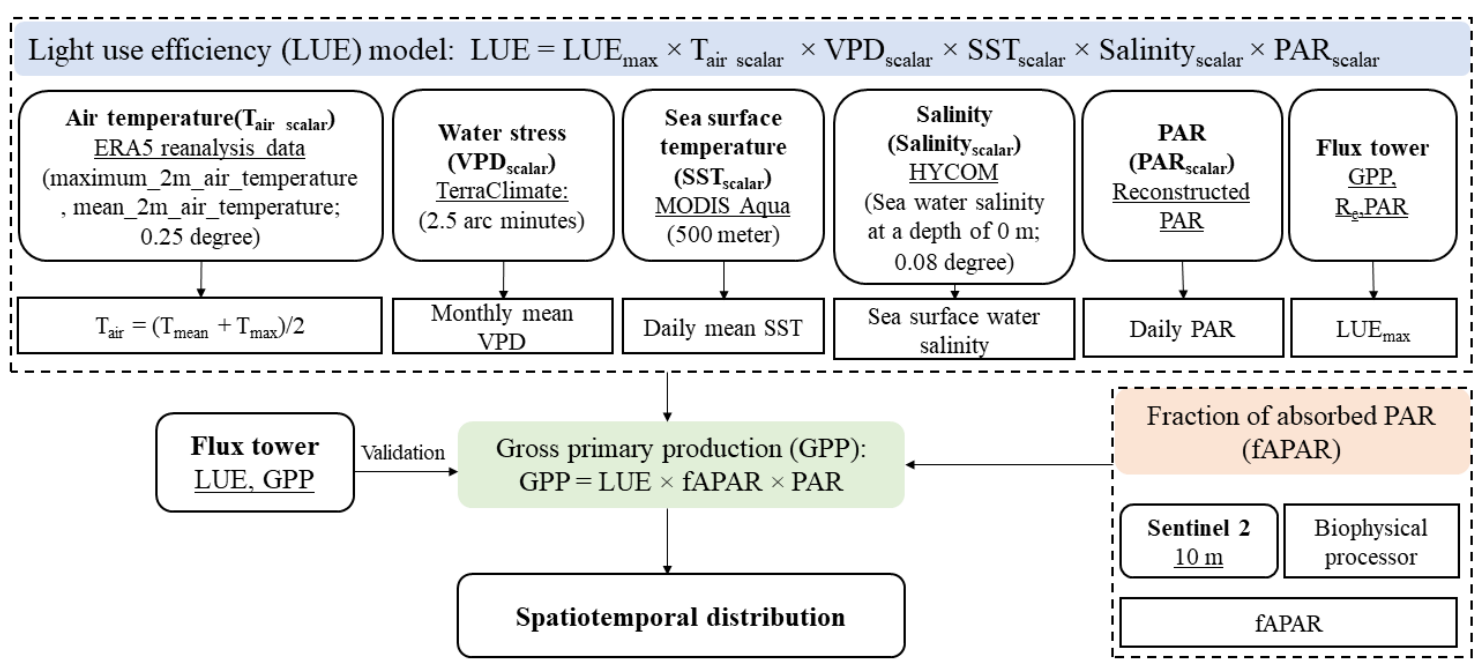

Figure 8. Overall flowchart of GPP modeling.

Then, fAPAR was computed using the biophysical processor in SNAP software ${ }^{65}$. The processed Sentinel-2 fAPAR products (fAPAR-S2) represent the daily integrated fAPAR values, following the assumption that the instantaneous fAPAR value at 10:00 (or 14:00) solar time is close to the daily integrated value under clear sky conditions ${ }^{66}$. Besides, outlier pixels in fAPAR-S2 were 
eliminated and only pixels with "QA= 000 " were adopted.

After that, reconstructed PAR data were obtained from 724 meteorological stations provided by Tang, et al. ${ }^{53}$ ). We further interpolated the PAR data from meteorological stations to the whole coastal zone by the Co-Kriging interpolation method ${ }^{67}$ taking surface elevation as covariate ${ }^{68,69}$. Finally, GPP in these two mangrove reserves was estimated based on the derived LUE, fAPAR, and PAR.

\section{Model validation and application}

The LUE results modeled with hourly and daily environmental data were validated with the LUE values from the carbon fluxes tower in the Zhangjiang mangrove reserve. Moreover, LUE was estimated following the LUE model for terrestrial forests considering only the effects of $T_{\text {air }}$ and VPD as shown in Eq. (1). The experimental results were also compared with in-situ LUE to evaluate the performance. GPP estimated using the proposed model was validated with the flux tower measurements. The GPP derived considering coastal environments was in turn converted to a cumulative 8-day composite and compared with MODIS GPP product at the same resolution ${ }^{70}$.

After validation, the GPP model was applied to estimate the GPP of the mangrove forests in the whole coastal zone of China for the years 2007, 2010, and 2018. Besides, seasonal variations were displayed to reflect the different productivity of mangroves under various environmental conditions.

\section{Data availability}

The datasets generated during and/or analyzed during the current study are available from the corresponding author on reasonable request.

\section{References}

1 Duarte, C. M., Losada, I. J., Hendriks, I. E., Mazarrasa, I. \& Marbà, N. The role of coastal plant communities for climate change mitigation and adaptation. Nature Climate Change $\mathbf{3}$, 961-968 (2013).

2 Law, B., Waring, R., Anthoni, P. \& Aber, J. Measurements of gross and net ecosystem productivity and water vapour exchange of a Pinus ponderosa ecosystem, and an evaluation of two generalized models. Global Change Biology 6, 155-168 (2000).

3 Lees, K. J. et al. Assessing the reliability of peatland GPP measurements by remote sensing: From plot to landscape scale. Science of the Total Environment 766, 142613 (2021).

4 Prince, S. D. \& Goward, S. N. Global primary production: a remote sensing approach. Journal of biogeography, 815-835 (1995).

5 Running, S. W., Nemani, R., Glassy, J. M. \& Thornton, P. E. MODIS daily photosynthesis (PSN) and annual net primary production (NPP) product (MOD17) Algorithm Theoretical Basis Document. University of Montana, SCF At-Launch Algorithm ATBD Documents (available online at: www. ntsg. umt. edu/modis/ATBD/ATBD_MOD17_v21.pdf) 490 (1999).

6 Running, S. W. et al. A continuous satellite-derived measure of global terrestrial primary production. Bioscience 54, 547-560 (2004).

7 Verstraeten, W. W., Veroustraete, F. \& Feyen, J. On temperature and water limitation of net ecosystem productivity: Implementation in the C-Fix model. Ecological Modelling 199, 4-22 (2006). 
Zhang, Y. \& Ye, A. Would the obtainable gross primary productivity (GPP) products stand up? A critical assessment of 45 global GPP products. Science of The Total Environment $\mathbf{7 8 3}$, 146965 (2021).

9 Wang, S., Zhang, Y., Ju, W., Qiu, B. \& Zhang, Z. Tracking the seasonal and inter-annual variations of global gross primary production during last four decades using satellite nearinfrared reflectance data. Science of the Total Environment 755, 142569 (2021).

10 Alongi, D. M. Present state and future of the world's mangrove forests. Environmental conservation, 331-349 (2002).

11 Devaney, J. L., Pullen, J., Feller, I. C. \& Parker, J. D. Low humidity and hypersalinity reduce cold tolerance in mangroves. Estuarine, Coastal and Shelf Science 248, 107015 (2021).

12 Quisthoudt, K. et al. Temperature variation among mangrove latitudinal range limits worldwide. Trees 26, 1919-1931 (2012).

13 Barr, J. G., Engel, V., Fuentes, J., Fuller, D. \& Kwon, H. Modeling light use efficiency in a subtropical mangrove forest equipped with CO 2 eddy covariance. Biogeosciences 10, 21452158 (2013).

14 Krauss, K. W. \& Allen, J. A. Influences of salinity and shade on seedling photosynthesis and growth of two mangrove species, Rhizophora mangle and Bruguiera sexangula, introduced to Hawaii. Aquatic botany 77, 311-324 (2003).

15 Barr, J. G., Fuentes, J. D., Engel, V. \& Zieman, J. C. Physiological responses of red mangroves to the climate in the Florida Everglades. Journal of Geophysical Research: Biogeosciences 114 (2009).

16 Noor, T., Batool, N., Mazhar, R. \& Ilyas, N. Effects of siltation, temperature and salinity on mangrove plants. European Academic Research 2, 14172-14179 (2015).

17 Cui, X. et al. Stronger ecosystem carbon sequestration potential of mangrove wetlands with respect to terrestrial forests in subtropical China. Agricultural and Forest Meteorology 249, $71-80$ (2018).

18 Boto, K. G. \& Wellington, J. T. Seasonal variations in concentrations and fluxes of dissolved organic and inorganic materials in a tropical, tidally-dominated, mangrove waterway. Marine Ecology Progress Series, 151-160 (1988).

19 Rodda, S. R., Thumaty, K. C., Jha, C. S. \& Dadhwal, V. K. Seasonal variations of carbon dioxide, water vapor and energy fluxes in tropical Indian mangroves. Forests 7, 35 (2016).

20 Romigh, M. M., Davis, S. E., Rivera-Monroy, V. H. \& Twilley, R. R. Flux of organic carbon in a riverine mangrove wetland in the Florida Coastal Everglades. Hydrobiologia 569, 505516 (2006).

21 Alongi, D. M., Boto, K. G. \& Tirendi, F. Effect of exported mangrove litter on bacterial productivity and dissolved organic carbon fluxes in adjacent tropical nearshore sediments. Marine ecology progress series. Oldendorf 56, 133-144 (1989).

22 Alvarado-Barrientos, M. S., López-Adame, H., Lazcano-Hernández, H. E., Arellano-Verdejo, J. \& Hernández-Arana, H. A. Ecosystem-Atmosphere Exchange of CO2, Water, and Energy in a Basin Mangrove of the Northeastern Coast of the Yucatan Peninsula. Journal of Geophysical Research: Biogeosciences 126, e2020JG005811 (2021).

23 Dittmar, T. \& Lara, R. Driving forces behind nutrient and organic matter dynamics in a 

(2001).

24 Knox, S., Windham-Myers, L., Anderson, F., Sturtevant, C. \& Bergamaschi, B. Direct and indirect effects of tides on ecosystem-scale $\mathrm{CO} 2$ exchange in a brackish tidal marsh in Northern California. Journal of Geophysical Research: Biogeosciences 123, 787-806 (2018). 25 Lele, N. et al. Seasonal variation in photosynthetic rates and satellite-based GPP estimation over mangrove forest. Environmental Monitoring and Assessment 193, 1-20 (2021).

26 Moore, R., Miller, P., Ehleringer, J. \& Lawrence, W. Seasonal trends in gas exchange characteristics of three mangrove species. Photosynthetica (1973).

27 Barr, J. G., DeLonge, M. S. \& Fuentes, J. D. Seasonal evapotranspiration patterns in mangrove forests. Journal of Geophysical Research: Atmospheres 119, 3886-3899 (2014).

28 Sánchez-Núñez, D. A. \& Mancera-Pineda, J. E. Flowering patterns in three neotropical mangrove species: Evidence from a Caribbean island. Aquatic Botany 94, 177-182 (2011).

29 Barr, J. G. et al. Controls on mangrove forest-atmosphere carbon dioxide exchanges in western Everglades National Park. Journal of Geophysical Research: Biogeosciences 115 (2010).

30 Zhu, X., Song, L., Weng, Q. \& Huang, G. Linking in situ photochemical reflectance index measurements with mangrove carbon dynamics in a subtropical coastal wetland. Journal of Geophysical Research: Biogeosciences 124, 1714-1730 (2019).

31 Ximenes, A. C., Ponsoni, L., Lira, C. F., Koedam, N. \& Dahdouh-Guebas, F. Does sea surface temperature contribute to determining range limits and expansion of mangroves in eastern South America (Brazil)? Remote Sensing 10, 1787 (2018).

32 Gnanamoorthy, P. et al. Seasonal variations of net ecosystem (CO2) exchange in the Indian tropical mangrove forest of Pichavaram. Estuarine, Coastal and Shelf Science 243, 106828 (2020).

33 Goulden, M. L. et al. Physiological responses of a black spruce forest to weather. Journal of Geophysical Research: Atmospheres 102, 28987-28996 (1997).

34 Wang, Z., Xiao, X. \& Yan, X. Modeling gross primary production of maize cropland and degraded grassland in northeastern China. Agricultural and Forest Meteorology 150, 11601167 (2010).

35 Running, S. W. \& Zhao, M. Daily GPP and annual NPP (MOD17A2/A3) products NASA Earth Observing System MODIS land algorithm. MOD17 User's Guide 2015, 1-28 (2015).

36 Bjorkman, O., Demmig, B. \& Andrews, T. J. Mangrove photosynthesis: response to highirradiance stress. Functional Plant Biology 15, 43-61 (1988).

37 Ball, M. C. \& Critchley, C. Photosynthetic responses to irradiance by the grey mangrove, Avicennia marina, grown under different light regimes. Plant Physiology 70, 1101-1106 (1982).

38 Chen, L. et al. Comparison of ecophysiological characteristics between introduced and indigenous mangrove species in China. Estuarine, Coastal and Shelf Science 79, 644-652 (2008).

39 Li, L., Wu, X. \& Liu, S. Characteristics of photosynthesis and photosynthetic carbon fixation capacity of five mangrove tree species in Zhanjiang City. Guangxi Zhiwu/Guihaia 35, 825- 
40 Liu, B. \& Liao, B. The Physio-ecological Response of Acanthus ilicifolius Seedlings to Different Degrees of Light Intensity in Tide Environment. Forest Research 26, 192-199 (2013).

41 Xiao, X. et al. Satellite-based modeling of gross primary production in a seasonally moist tropical evergreen forest. Remote Sensing of Environment 94, 105-122 (2005).

Chen, H., Lu, W., Yan, G., Yang, S. \& Lin, G. Typhoons exert significant but differential impacts on net ecosystem carbon exchange of subtropical mangrove forests in China. Biogeosciences 11, 5323-5333 (2014).

43 Cui, X., Lin, G., Liang, J., Song, W. \& Zhou, J. in EGU General Assembly Conference Abstracts. 148.

44 Liu, J. \& Lai, D. Y. Subtropical mangrove wetland is a stronger carbon dioxide sink in the dry than wet seasons. Agricultural and Forest Meteorology 278, 107644 (2019).

45 Gnanamoorthy, P., Selvam, V., Chakraborty, S., Pramit, D. \& Karipot, A. in Proceedings of International Forestry and Environment Symposium, Sri Lanka. https://doi. org/10.31357/fesympo. v22i0.

46 Sun, Z. et al. Evaluating and comparing remote sensing terrestrial GPP models for their response to climate variability and CO2 trends. Science of the total environment $\mathbf{6 6 8}, 696-713$ (2019).

47 Wang, M., Sun, R., Zhu, A. \& Xiao, Z. Evaluation and Comparison of Light Use Efficiency and Gross Primary Productivity Using Three Different Approaches. Remote Sensing 12, 1003 (2020).

48 Xiao, X. et al. Satellite-based modeling of gross primary production in an evergreen needleleaf forest. Remote sensing of environment 89, 519-534 (2004).

49 Gobron, N. Report on satellite derived ECV definition and field protocols. (2015).

50 Apeh, O. O., Overen, O. K. \& Meyer, E. L. Monthly, Seasonal and Yearly Assessments of Global Solar Radiation, Clearness Index and Diffuse Fractions in Alice, South Africa. Sustainability 13, 2135 (2021).

51 Ma, S. \& Zhu, C. Extreme cold wave over East Asia in January 2016: A possible response to the larger internal atmospheric variability induced by Arctic warming. Journal of Climate 32, 1203-1216 (2019).

52 Mo, D., Hou, Y., Li, J. \& Liu, Y. Study on the storm surges induced by cold waves in the Northern East China Sea. Journal of Marine Systems 160, 26-39 (2016).

53 Tang, L. et al. Reconstructed data of photosynthetically active radiation in China (1961-2014). (2017).

54 Zheng, Y. \& Takeuchi, W. Quantitative Assessment and Driving Force Analysis of Mangrove Forest Changes in China from 1985 to 2018 by Integrating Optical and Radar Imagery. ISPRS International Journal of Geo-Information 9, 513 (2020).

5 Potter, C. S. et al. Terrestrial ecosystem production: a process model based on global satellite and surface data. Global Biogeochemical Cycles 7, 811-841 (1993).

56 Ruimy, A., Saugier, B. \& Dedieu, G. Methodology for the estimation of terrestrial net primary production from remotely sensed data. Journal of Geophysical Research: Atmospheres 99, 

5263-5283 (1994).

58757 Xiao, X. et al. Modeling gross primary production of temperate deciduous broadleaf forest $588 \quad$ using satellite images and climate data. Remote sensing of environment 91, 256-270 (2004).

$58958 \quad$ Hogarth, P. J. The biology of mangroves and seagrasses. (Oxford University Press, 2015).

59059 Leopold, A. et al. Net ecosystem CO2 exchange in the "Coeur de Voh" mangrove, New 591 Caledonia: Effects of water stress on mangrove productivity in a semi-arid climate. Agricultural and forest meteorology 223, 217-232 (2016).

60 Li, A., Bian, J., Lei, G. \& Huang, C. Estimating the maximal light use efficiency for different

\section{Acknowledgements}

620 The authors would like to thank Professor Guanghui Lin from Tsinghua University, China, and 621 Professor Xudong Zhu from Xiamen University for sharing the carbon flux data in Zhangjiang and Zhanjiang mangrove reserves, and Professor Bo Hu from Chinese Academy of Sciences, China for sharing the reconstructed PAR data in China. This study was in part supported by the China 624 Scholarship Council.

\section{Author contributions statement}


626 Y. Z.: Conceptualization, Methodology, Software, Validation, Formal analysis, Investigation, 627 Data Curation, Writing- Original Draft, and Visualization. W. T.: Resources, Writing- Review and 628 Editing, Supervision, and Project administration.

\section{Competing interests}

630 The authors declare no competing interests. 


\section{Supplementary Files}

This is a list of supplementary files associated with this preprint. Click to download.

- SupplementaryMaterials.docx 